\title{
ANALISIS TINGKAT KEPUASAN PETANI TERHADAP BENIH PADI (Oryza sativa, L) VARIETAS PB 42 DI KECAMATAN MANYAK PAYED KABUPATEN ACEH TAMIANG
}

\author{
ABDURRACHMAN $1 /$ FERIANDA ${ }^{2}$ \\ 1Dosen Tetap Program Studi Agribisnis Fakultas Pertanian \\ 2Mahasiswa Fakultas Pertanian Program Studi Agribisnis \\ Universitas Samudra, Langsa-Aceh
}

\begin{abstract}
ABSTRAK
Permasalahan penelitian ini adalah seberapa besar Tingkat Kepuasan Petani Terhadap Benih Padi (Oryza sativa, L) Varietas PB 42 di Kecamatan Manyak Payed Kabupaten Aceh Tamiang. Tujuan penelitian adalah untuk mengetahui Tingkat Kepuasan Petani Terhadap Benih Padi (Oryza sativa, L) Varietas PB 42 di Kecamatan Manyak Payed Kabupaten Aceh Tamiang.Penelitian menggunakan metode survey. Objek penelitian ini adalah petani padi sawah sebagai konsumen benih padi varietas PB42, keputusan pembelian, atribut produk dan tingkat kepuasan petani. Ruang lingkup penelitian ini hanya mengkaji dan menganalisis proses keputusan pembelian dan tingkat kepuasan petani terhadap benih padi varietas PB42 di lokasi penelitian. Penelitian dilaksanakan pada bulan November s.d. Desember 2014

Petani sampel adalah sebanyak 32 orang dengan rincian desa Seunebeuk Baru sebanyak 7 orang, desa Lhok Medang Ara sebanyak 6 orang, desa Tualang Baru sebanyak 6 orang, desa Alue Sentang sebanyak 8 orang dan desa Paya Baru sebanyak 5 orang.

Hasil penelitian: Karakteristik petani sampel di lokasi penelitian kelompok umur berkisar antara 46-51 tahun sebesar $40.63 \%$. Pendidikan petani sampel sebagian besar responden adalah lulusan Sekolah Dasar sebesar 65,63 \%. Kisaran pendapatan terbanyak sebesar Rp. 1,1 juta s.d. Rp. 3,0 juta per musim tanam sebesar 56,26 \%. Pengalaman rata-rata petani sampel menanam padi PB 42 yaitu 12,13 tahun. status lahan sebagai pemilik yaitu sebanyak 25 orang (78,13\%), sisanya sebanyak 7 orang $(21,88 \%)$ sebagai petani penggarap saja. Luas lahan garapan 1.000 s.d. $5.500 \mathrm{~m}^{2}$ sebanyak 26 petani (81,26 \%), untuk luas lahan 5.600 s.d. $10.000 \mathrm{~m}^{2}$ sebanyak 6 petani $(18,75 \%)$.

Petani sampel yang masih menggunakan benih padi varietas PB42 menyatakan biasa saja ketika membeli benih varietas PB42 (46,88\%), informasi tentang benih PB42 berasal dari petani lain dan keluarga $(87,5 \%)$, petani memutuskan sendiri untuk membeli benih PB42 (87,5\%), petani tertarik dengan harga benih PB42 karena lebih murah harganya (46,88\%), petani membeli benih lain yaitu Ciherang dan Mekongga (68,75\%), $75 \%$ petani membeli benih PB42 di kios pertanian terdekat, 71,88\% petani membeli benih Pb42 berdasarkan situasi, $68,75 \%$ petani merasa biasa saja ketika tidak membeli benih PB42, 40,63\% petani menyatakan benih PB42 tidak tahan lagi terhadap hama dan penyakit, $71,88 \%$ petani membeli benih lain ketika benih PB42 tidak tersedia dan dari 13 atribut yang dimiliki oleh benih padi varietas PB42 hanya atribut daya tumbuh dan tahan rebah yang dianggap penting dan memuaskan petani sampel di daerah penelitian.

Kesimpulan penelitian berdasarkan hasil perhitungan indeks kepuasan konsumen (CSI) petani responden sebesar 38,547\% (0,3854) artinya secara keseluruhan menyatakan atribut yang dimiliki benih padi varietas PB42 kurang memuaskan petani di lokasi penelitian.
\end{abstract}

Kata Kunci: Padi, Atrbut, Varietas PB 42, Kebutuhan, Kepuasan Petani

\section{PENDAHULUAN}

Meningkatnya angka pertumbuhan jumlah penduduk di Indonesia merupakan salah satu tantangan berat yang harus dihadapi oleh sektor pertanian karena dengan pertambahan penduduk, pertumbuhan ekonomi, peningkatan daya beli pasar, dan perubahan selera masyarakat maka permintaan pangan akan semakin meningkat dalam jumlah, mutu dan keragamannya khususnya padi. Padi memegang peranan penting karena produk olahannya merupakan bahan makanan pokok sebagian besar penduduk di Indonesia.

Penyediaan benih padi unggul yang bermutu dan secara kontinyu dapat memenuhi permintaan petani, dapat membantu para petani untuk meningkatkan hasil produksi tanaman padi. Benih pagi unggul yang beredar harus memiliki sifat-sifat unggul, karena dengan benih unggul dapat membantu petani mengurangi resiko kegagalan panen.

Pemenuhan kepuasan (preferensi) petani yang tergambarkan dari kuantitas dan kualitas produksi memiliki hubungan yang sangat erat dan positif dengan penyediaan benih dari padi yang diminta. Potensi varietas yang dicirikan dengan penampilan padi dilapang berupa karakteristik produksi dilapang dan kualitas harus benar-benar memenuhi selera petani tersebut. Para produsen benih harus dapat menciptakan varietas yang dapat sesuai dan tepat untuk memenuhi kebutuhan yang dimaksud (Zacky, 2005:20).

Kecamatan Manyak Payed merupakan kecamatan yang memiliki tingkat produktivitas padi sawah yang tinggi dibandingkan dengan kecamatan lainnya yang ada di Kabupaten Aceh Tamiang. Pemilihan daerah penelitian di Kecamatan Mayak Payed karena kecamatan ini berpotensi sebagai sentra produksi padi sawah 
di Kabupaten Aceh Tamiang dan petani di daerah ini masih banyak menggunakan varietas PB42.Perilaku konsumen yang dimulai dari tahap pengenalan kebutuhan hingga pasca pembelian terbilang kompleks. Namun seiring dengan perkembangan ilmu pengetahuan dan teknologi para ahli berusaha untuk dapat memahami perilaku konsumen karena hal ini merupakan kunci keberhasilan suatu perusahaan. Perilaku konsumen penting untuk dipahami karena jika suatu perusahaan telah memahami prilaku konsumennya maka implikasinya mampu mempertahankan konsumen yang sudah ada dan mampu bertahan dipasar.

Di Kecamatan Manyak Payed benih padi varietas PB42 produksi PT Sang Hyang Seri bersaing dengan varietas-varietas padi lain produksi produsen benih di luar PT Sang Hyang Seri yang banyak di jual pada kios-kios pertanian. Oleh karena itu pengetahuan akan tingkat kepuasan petani terhadap benih padi varietas PB42 sangat penting untuk diketahui.

\section{METODE PENELITIAN}

Penelitian ini dilaksanakan di Kecamatan Manyak Payed Kabupaten Aceh Tamiang dengan menggunakan metode survey.Objek penelitian Tabel II-1: Jumlah Populasi dan Jumlah Sampel Petani Padi Sawah di Daerah Penelitian

\begin{tabular}{|r|l|r|c|}
\hline \multicolumn{1}{|c|}{ No } & \multicolumn{1}{|c|}{ Desa } & $\begin{array}{c}\text { Jumlah Petani } \\
\text { (Orang) }\end{array}$ & $\begin{array}{c}\text { Petani Sampel } \\
\text { (Orang) }\end{array}$ \\
\hline 1 & Seneueuk Baru & 24 & 7 \\
2 & Lhok Medang Ara & 21 & 6 \\
3 & Tualang Baru & 18 & 6 \\
4 & Alue Sentang & 26 & 8 \\
5 & Paya Baru & 17 & 32 \\
\hline
\end{tabular}

Sumber: Anonymous, 2014

Dari tabel II-1 di atas dapat dilihat bahwa jumlah petani sampel adalah sebanyak 32 orang dengan rincian desa Seunebeuk Baru sebanyak 7 orang, desa Lhok Medang Ara sebanyak 6 orang, desa Tualang Baru sebanyak 6 orang, desa Alue Sentang sebanyak 8 orang dan desa Paya Baru sebanyak 5 orang.

\section{Pengumpulan Data}

a) Data Primer

b) Data Sekunder

\section{Metode Analisis dan Pengujian Hipotesis}

1. Analisis Deskriptif

Hasil yang diperoleh diolah dengan menggunakan presentase berdasarkan jumlah responden. Presentase terbesar dari setiap hasil adalah faktor dominan dari masing-masing variabel yang dianalisis. Pengelompokan karakteristik konsumen meliputi data demografi seperti usia, jenis kelamin, pekerjaan, pendidikan, dan tingkat pendapatan serta AGRISAMUDRA, Jurnal Penelitian Vol.2 No. I Januari-Juni 2015 ini adalah petani padi sawah sebagai konsumen benih padi varietas PB42, keputusan pembelian, atribut produk dan tingkat kepuasan petani.

Ruang lingkup penelitian ini hanya mengkaji dan menganalisis proses keputusan pembelian dan tingkat kepuasan petani terhadap benih padi varietas PB42 di lokasi penelitian. Penelitian dilaksanakan pada bulan November s.d. Desember 2014.

\section{Penentuan Sampel dan Pengumpulan Data 1. Penentuan Sampel}

Kecamatan Manyak Payed terdiri dari 36 desa, dari 36 desa tersebut hanya 5 desa yang terdapat usahatani padi sawah dengan menggunakan benih padi varietas PB42 yaitu desa Seunebeuk Baru, desa Lhok Medang Ara, desa Tualang Baru, desa Alue Sentang dan desa Paya Baru. Ke 5 desa tersebut semua dijadikan desa sampel secara purposive sampling (sengaja)

Penentuan petani sampel dari masing-masing desa sampel ditentukan secara simple random sampling (sampel acak sederhana). Untuk lebih jelas jumlah populasi dan sampel masingmasing desa sampel dapat dilihat pada tabel II-1 berikut: 
TabellI.2.Skala Likert Untuk Tingkat Kepentingan dan Tingkat Kepuasan

\begin{tabular}{|c|l|l|}
\hline Nilai Skala & $\begin{array}{l}\text { Tingkat } \\
\text { Kepentingan }\end{array}$ & $\begin{array}{l}\text { Tingkat } \\
\text { Kepuasan }\end{array}$ \\
\hline 1 & Sangat Tidak & Sangat Tidak \\
& Penting & Puas \\
2 & Kurang Penting & Kurang Puas \\
3 & Cukup Penting & Cukup Puas \\
4 & Penting & Puas \\
5 & Sangat Penting & Sangat Puas \\
\hline
\end{tabular}

Penilaian tingkat kinerja yang dapat mempengaruhi kepuasan konsumen mewakili oleh huruf $X$, sedangkan untuk penilain tingkat kepentimgan ditunjukan oleh huruf $Y$. Sumbu mendatar $(X)$ akan diisi oleh skor tingkat kinerja, dan sumbu tegak (Y) akan diisi oleh skor tingkat kepentingan. Untuk setiap faktor yang mempengaruhi kepuasan pelanggan digunakan rumus:

Dimana :

$$
\overline{\mathrm{X}} \mathrm{i}=\frac{\sum \mathrm{Xi}}{\mathrm{n}} \overline{\mathrm{Y}} \mathrm{i}=\frac{\sum \mathrm{Yi}}{\mathrm{n}}
$$

$\overline{\mathrm{X}} \mathrm{i}=$ Nilai rata-rata tingkat kinerja atribut ke $\mathrm{i}$

$\bar{Y} i=$ Nilai rata-rata tingkat kepentingan atribut ke i

Y (Kepentingan)

$$
\begin{aligned}
& X i=\text { Total skor Tingkat Kepuasan Atribut ke } \mathrm{i} \\
& \mathrm{Yi}=\text { Total Skor Tingkat Kepentingan Atriut ke } \mathrm{i} \\
& \mathrm{n}=\text { Jumlah data petani }
\end{aligned}
$$

Diagram kartesius merupakan suatu bagan yang di bagi atas empat bagian yang dibatasi oleh dua buah garis yang berpotongan tegak lurus pada titik-titik $(X, Y)$, dimana $X$ merupakan rata-rata dari rata-rata tingkat pelaksanaan seluruh atribut dan $Y$ adalah rata-rata dari skor rata-rata tingkat kepentingan seluruh atribut yang mempengaruhi tingkat kepuasan. Masingmasing dihitung dengan rumus:

Dimana :

$$
\overline{\mathrm{X}}=\frac{\sum \overline{\mathrm{X}}}{\mathrm{k}} \overline{\overline{\mathrm{Y}}}=\frac{\sum \overline{\mathrm{Y}}}{\mathrm{k}}
$$

$\overline{\mathrm{X}}=$ Skor rata-rata dari rata-rata tingkat kinerja seluruh atribut

$\overline{\mathrm{Y}}=$ Skor rata-rata dari rata tingkat kepentingan seluruh atribut

$\mathrm{k}=$ Banyaknya atribut yang diteliti

Selanjutnya tingkat unsur-unsur tersebut akan dijabarkan dan di bagi menjadi empat bagian kedalam diagram kartesius seperti pada Gambar 2.

\begin{tabular}{|l|l} 
Perioritas Utama & Pertahankan Posisi \\
\hline Perioritas Rendah & Berlebihan \\
\hline
\end{tabular}

\section{$\overline{\mathrm{X}} \mathrm{X}($ Kinerja)}

\section{Tingkat Kepuasan Konsumen (Customers Satisfaction Indeks)}

Customers Satisfaction Indeks digunakan untuk mengetahui tingkat kepuasan konsumen secara menyeluruh dengan melihat tingkat kepentingan dari atribut-atribut produk dan jasa. Atributatribut yang di ukur dapat berbeda untuk masing-masing indrustri/perusahaan. Hal ini tergantung pada kebutuhan yang ingin didapatkan terhadap konsumen adapun cara untuk menghitung/mengukur CSI.

a) Menentukan Mean Importance Score (MIS) dan Mean Performance Score (MSS). Nilai ini berasal dari rata-rata tingkat kepentingan dan kinerja tiap konsumen.

$$
\frac{\mathrm{Yi}}{\mathrm{n}} \mathrm{n}_{\mathrm{i}=I}^{n} \mathrm{YiX \textrm {X }}=\sum_{i=I}^{n} \mathrm{Xi}
$$

Dengan: $n=$ jumlah konsumen

$\mathrm{Yi}=$ Nilai kepentingan atribut $\mathrm{X}$ ke- $\mathrm{i}$

$\mathrm{Xi}=$ Nilai kinerja atribut ke-i

b) Membuat Weight Factor (WF). Bobot merupakan persentase nilai MIS per atribut terhadap total MIS seluruh atribut.

$$
\mathrm{WF}=\frac{M I S i}{\sum_{\mathrm{i}=\mathrm{I}}^{\mathrm{p}} M I S i} X 100 \%
$$

Dimana $\mathrm{p}=$ Atribut kepentingan ke $-\mathrm{p}$

c) Membuat Wight Score (WS), bobot ini merupakan perkalian antara Weight Factors (WF) dengan Mean Performance (MSS) $\mathrm{WS}=\mathrm{WF} \times \mathrm{MSS}$

d) Customer Satisfaction Index (CSI), adalah rasio dari total weight score (WS) dibagi Highhest scale (HS) atau skala maksimum yang dipakai skala 5 dikali 100 persen.

$$
\mathrm{CSI}=\frac{\sum_{\mathrm{i}}^{\mathrm{p}} \mathrm{WS}}{\mathrm{HS}} \times 100 \%
$$

Dimana $: p=$ Atribut $-p$

$$
\mathrm{HS}=\text { Skala maksimum yang digunakan }
$$

Skala likert digunakan untuk mengukur tingkat kepentingan dan tingkat kepuasan konsumen terhadap suatu atribut-atribut yang ditanyakan. Pada penelitian ini rentang skala yang digunakan adalah:

$$
\mathrm{RS}=\frac{100 \%-0 \%}{5}
$$

Berdasarkan rentang skala tersebut maka kriteria kepuasan yang digunakan pada penelitian adalah Tabel II.3. 
Tabel II.3. Kriteria Nilai Custumers Sastification Index

\begin{tabular}{|l|c|c|}
\hline No & Rentang Skala & Keterangan \\
\hline 1 & $0 \%<\mathrm{CSI} \leq 20 \%$ & $\begin{array}{c}\text { Sangat Tidak } \\
\text { Puas } \\
\end{array}$ \\
2 & $20 \%<\mathrm{CSI} \leq 40 \%$ & Kurang Puas \\
3 & $40 \%<\mathrm{CSI} \leq 60 \%$ & Cukup Puas \\
4 & $60 \%<\mathrm{CSI} \leq 80 \%$ & Puas \\
5 & $80 \%<\mathrm{CSI} \leq 100 \%$ & Sangat Puas \\
\hline
\end{tabular}

\section{HASIL DAN PENELITIAN}

Karakteristik Petani Sampel

\section{Karakteristik Petani Sampel Berdasarkan Umur}

Petani sampel dalam penelitian ini sangat beragam apabila dilihat dari karakteristik berdasarkan umur. Berdasarkan hasil penelitian menunjukan bahwa proporsi terbesar dalam kelompok umur berkisar antara 46-51 tahun sebesar 40.63 persen.

\section{Karakteristik Petani Sampel Berdasarkan Alamat}

Data hasil penelitian berdasarkan alamat responden diperoleh data 7 orang petani dari Desa Seneubeuk Baru, 6 orang dari Desa Lhok Medang Ara, 6 orang dari Desa Tualang Baru, 8 orang dari Desa Alue Sentang dan 5 orang dari Desa Paya Baru dimana di desa tersebut kebanyakan bermatapencaharian petani khususnya petani padi.

\section{Karakteristik Petani Sampel Berdasarkan Pendidikan Terakhir}

Tingkat pendidikan petani responden akan sangat berpengaruh terhadap tingkat penyerapan teknologi baru dan ilmu pengetahuan. Dari segi pendidikan berdasarkan hasil penelitian menunjukan bahwa sebagian besar responden adalah Iulusan Sekolah Dasar sebesar $65,63 \%$.

\section{Karakteristik Petani Sampel Berdasarkan}

Rata-Rata Pendapatan Permusim Tanam Berdasarkan hasil penelitian menunjukan bahwa kisaran pendapatan

Tabel IV.8. Sebaran Persentase Petani Sampel Berdasarkan Motivasi Pembelian

\begin{tabular}{|l|c|c|}
\hline \multicolumn{1}{|c|}{ Motivasi Dalam Pembelian Benih Padi PB 42 } & Petani Sampel (Orang) & Persentase (\%) \\
\hline Produksi Tinggi & 6 & 18.75 \\
Kualitas Tinggi & 5 & 15.63 \\
Tahan Hama dan Penyakit & 2 & 6.25 \\
Permintaan Tinggi & 5 & 15.63 \\
Daya Tumbuh & 4 & 12.50 \\
Mudah didapat & 5 & 15.63 \\
Sudah Biasa Menanam & 4 & 12.50 \\
Ingin Mencoba & 1 & 3.13 \\
\hline Jumlah & 32 & 100.00 \\
\hline
\end{tabular}

Sumber: Data Primer Diolah 2014

\section{Pencarian Informasi}

terbanyak sebesar Rp. 1,1 juta s.d. Rp. 3,0 juta per musim tanam sebanyak 18 petani sebesar $56,26 \%$. Perbedaan pendapatan dari masingmasing petani tersebut dikarenakan adanya perbedaan luas lahan sehingga berbeda pendapatan per musim tanam.

\section{Karakteristik Petani Sampel Berdasarkan Lamanya Mananam Padi PB 42}

Dari 32 petani sampel merupakan petani yang telah lama berusahatani padi PB 42 (> 9 tahun). Pengalaman rata-rata petani sampel menanam padi PB 42 yaitu 12,13 tahun.

\section{Karakteristik Petani Sampel Berdasarkan Status Lahan \\ Berdasarkan data petani sampel,} sebagai pemilik yaitu sebanyak 25 orang $(78,13$ $\%)$, sisanya sebanyak 7 orang (21,88 \%) sebagai petani penggarap saja. Rata-rata lahan petani adalah lahan sawah dengan irigasi yang teratur sehingga kebutuhan air dapat di atur sesuai dengan kebutuhan tanaman padi.

\section{Karakteristik Petani Sampel Berdasarkan Luas lahan Yang Digarap}

Luas lahan yang di garap oleh para petani padi di Kecamatan Manyak Payed bekisar $1.500 \mathrm{~s} / \mathrm{d} 10.000 \mathrm{~m}^{2}$. Luas lahan tersebut masih jauh lebih kecil jika dibandingkan dengan luas lahan para petani yang ideal untuk usahatani padi yang menguntungkan. Hal ini di karenakan sempitnya lahan pertanian di daerah penelitian. Persentase yang paling besar berada pada luasan 1.000 s.d. $5.500 \mathrm{~m}^{2}$ sebanyak 26 petani $(81,26 \%)$, untuk luas lahan 5.600 s.d. $10.000 \mathrm{~m}^{2}$ sebanyak 6 petani $(18,75 \%)$.

\section{B. Proses Pengambilan Keputusan Pembelian Benih Padi PB 42}

\section{Pengenalan Kebutuhan}

Sebaran persentase motivasi petani sampel dapat dilihat pada Tabel berikut. sebagian besar petani memiliki status lahan 
Tabel IV.10. Sebaran Persentase Petani Sampel Berdasarkan Informasi tentang Benih Padi Varietas PB 42

\begin{tabular}{|l|c|c|}
\hline \multicolumn{1}{|c|}{ Informasi Tentang Benih PB 42 } & Petani Sampel (Orang) & Persentase (\%) \\
\hline Kelompok Tani & 2 & 6.25 \\
Media Massa & 1 & 3.13 \\
Brosur & 1 & 3.13 \\
Petani Lain & 10 & 31.25 \\
Keluarga & 18 & 56.25 \\
\hline Jumlah & 32 & 100.00 \\
\hline
\end{tabular}

Sumber: Data Primer diolah, 2014

Tabel IV.11. Sebaran Persentase Petani Sampel Berdasarkan Sumber Informasi yang Dibutuhkan Dalam Menentukan Pembelian

\begin{tabular}{|l|c|c|}
\hline \multicolumn{1}{|c|}{$\begin{array}{c}\text { Sumber Informasi } \\
\text { Benih PB 42 }\end{array}$} & $\begin{array}{c}\text { Petani Sampel } \\
\text { (orang) }\end{array}$ & $\begin{array}{c}\text { Persentase } \\
(\%)\end{array}$ \\
\hline Diri Sendiri & 29 & 90.63 \\
Kelompok Tani & 0 & 0.00 \\
Penangkar Benih & 0 & 0.00 \\
PPL & 0 & 0.00 \\
Kios Saprotan & 3 & 9.38 \\
\hline Jumlah & 32 & 100.00 \\
\hline
\end{tabular}

Sumber: Data Primer diolah, 2014

\section{Evaluasi Alternatif}

Tabel IV.12. Sebaran Persentase Petani Sampel Berdasarkan Atribut yang menjadi Fokus perhatian dari Benih Padi PB 42

\begin{tabular}{|l|r|r|}
\hline \multicolumn{1}{|c|}{$\begin{array}{c}\text { Atribut Yang Menjadi Perhatian } \\
\text { Benih PB 42 }\end{array}$} & $\begin{array}{c}\text { Petani Sampel } \\
\text { (orang) }\end{array}$ & $\begin{array}{c}\text { Persentase } \\
\text { (\%) }\end{array}$ \\
\hline Harga & 15 & 46.88 \\
Merek dan Kemasan & 2 & 6.25 \\
Kemudahan Memperoleh & 5 & 15.63 \\
Produktivitas & 4 & 12.50 \\
Kualitas Beras & 6 & 18.75 \\
\hline
\end{tabular}

Sumber: Data Primer Diolah, 2014

Tabel IV.13.Sebaran Persentase Petani Sampel Berdasarkan Jenis Padi Bersertifikat yang Pernah Dibeli Selain Varietas PB 42

\begin{tabular}{|l|r|r|}
\hline \multicolumn{1}{|c|}{$\begin{array}{c}\text { Atribut Yang Pernah dibeli } \\
\text { Selain Benih PB 42 }\end{array}$} & $\begin{array}{c}\text { Petani Sampel } \\
\text { (orang) }\end{array}$ & \multicolumn{2}{|c|}{$\begin{array}{c}\text { Persentase } \\
\text { (\%) }\end{array}$} \\
\hline Mekongga & 10 & 31.25 \\
Impari & 7 & 21.88 \\
Ciherang & 12 & 37.50 \\
Lainnya & 3 & 9.38 \\
\hline
\end{tabular}

Sumber: Data Primer diolah, 2014

\section{Keputusan Pembelian}

Tahapan selanjutnya petani padi (konsumen) akan memutuskan untuk pembelian dan penggunan terhadap produk tersebut. Variabel yang dinilai dalam keputusan pembelian dapat memenuhi kebutuhan atau selera responden, merupakan pilihan terbaik dari alternatif yang ada sehingga akan dibeli oleh responden. Responden sampai pada tahap proses pembelian suatu produk atau jasa yang digunakan. Data sebaran tempat petani sampel 
Tabel IV.14. Sebaran Persentase Petani Sampel Berdasarkan dimana biasa membeli benih padi varietas PB 42

\begin{tabular}{|l|c|c|}
\hline \multicolumn{1}{|c|}{$\begin{array}{c}\text { Tempat Pembelian } \\
\text { Benih Padi PB 42 }\end{array}$} & $\begin{array}{c}\text { Petani Sampel } \\
\text { (orang) }\end{array}$ & $\begin{array}{c}\text { Persentase } \\
\text { (\%) }\end{array}$ \\
\hline Produsen Langsung & 0 & 0.00 \\
Kios Saprotan & 4 & 12.50 \\
Kios Pertanian Terdekat & 24 & 75.00 \\
Kelompok Tani & 4 & 12.50 \\
\hline Jumlah & 32 & 100.00 \\
\hline
\end{tabular}

Sumber: Data Primer diolah, 2014

Tabel IV.15.Sebaran Persentase Petani Sampel Cara Memutuskan Pembelian benih padi varietas PB 42 Berdasarkan Situasi

\begin{tabular}{|l|c|c|}
\hline \multicolumn{1}{|c|}{$\begin{array}{c}\text { Cara Memutuskan Membeli } \\
\text { Benih Padi PB 42 }\end{array}$} & $\begin{array}{c}\text { Petani Sampel } \\
\text { (orang) }\end{array}$ & $\begin{array}{c}\text { Persentase } \\
\text { (\%) }\end{array}$ \\
\hline Terencana & 4 & 12.50 \\
Mendadak & 5 & 15.63 \\
Tergantung Situasi & 23 & 71.88 \\
\hline Jumlah & 32 & 100.00 \\
\hline
\end{tabular}

Sumber: Data Primer diolah, 2014

Tabel IV.16. Sebaran Persentase Petani Sampel Berdasarkan Faktor Pihak yang Berpengaruh Dalam Memutuskan Pembelian

\begin{tabular}{|l|c|c|}
\hline \multicolumn{1}{|c|}{$\begin{array}{c}\text { Pihak Yang Berpengaruh Dalam } \\
\text { Keputusan Membeli PB 42 }\end{array}$} & $\begin{array}{c}\text { Petani Sampel } \\
\text { (orang) }\end{array}$ & $\begin{array}{c}\text { Persentase } \\
\text { (\%) }\end{array}$ \\
\hline Teman & 6 & 18.75 \\
Keinginan Sendiri & 14 & 43.75 \\
Keluarga/Saudara & 10 & 31.25 \\
Pedagang Pengumpul & 2 & 6.25 \\
\hline Jumlah & 32 & 100.00 \\
\hline
\end{tabular}

Sumber: Data Primer diolah, 2014

\section{Evaluasi Pasca Pembelian}

Tabel IV.17. Sebaran Persentase Pateni Sampel Berdasarkan Faktor Perasaan Jika Tidak Membeli Benih Padi Varietas PB 42

\begin{tabular}{|l|c|c|}
\hline \multicolumn{1}{|c|}{$\begin{array}{c}\text { Faktor Perasaan Jika Tidak } \\
\text { Membeli benih PB 42 }\end{array}$} & $\begin{array}{c}\text { Petani Sampel } \\
\text { (orang) }\end{array}$ & $\begin{array}{c}\text { Persentase } \\
\text { (\%) }\end{array}$ \\
\hline Merasa ada yang kurang & 8 & 25.00 \\
Biasa saja & 22 & 68.75 \\
Lainnya & 2 & 6.25 \\
\hline
\end{tabular}

Sumber: Data Primer diolah, 2015

Tabel IV.18. Sebaran Persentase Petani Sampel Berdasarkan Pengalaman Penggunaan benih padi varietas PB 42 Hal yang Perlu ditingkatkan 


\begin{tabular}{|l|c|c|}
\hline \multicolumn{1}{|c|}{$\begin{array}{c}\text { Hal Yang Perlu Ditingkatan } \\
\text { Dari Benih PB 42 }\end{array}$} & $\begin{array}{c}\text { Petani Sampel } \\
\text { (orang) }\end{array}$ & $\begin{array}{c}\text { Persentase } \\
(\%)\end{array}$ \\
\hline Harga & 5 & 15.63 \\
Merek dan Kemasan & 6 & 18.75 \\
Potensi Panen/Produktivitas & 5 & 15.63 \\
Ketahanan HPT & 13 & 40.63 \\
Kemudahan Memperoleh & 3 & 9.38 \\
\hline Jumlah & 32 & 100.00 \\
\hline
\end{tabular}

Tabel IV.19. Sebaran Persentase Petani Sampel Berdasarkan Faktor Ketidaktersediaan Benih di Lapang

\begin{tabular}{|l|r|r|}
\hline \multicolumn{1}{|c|}{$\begin{array}{c}\text { Ketidaktersediaan } \\
\text { Benih padi PB 42 }\end{array}$} & $\begin{array}{c}\text { Jumlah Responden } \\
\text { (orang) }\end{array}$ & $\begin{array}{c}\text { Persentase } \\
\text { (\%) }\end{array}$ \\
\hline Menggunakan benih sendiri & 7 & 21.88 \\
Menggunakan varietas lain & 23 & 71.88 \\
Tidak membeli & 2 & 6.25 \\
\hline Jumlah & 32 & 100.00 \\
\hline
\end{tabular}

Sumber: Data Primer diolah, 2014

\section{Importance Performance Analysis(IPA)}

Langkah pertama yang dilakukan adalah dengan melakukan perhitungan penilaian dari masing-masing atribut terhadap tingkat kepentingan dan tingkat kinerja. Setelah itu dilakukan perhitungan nilai rata-rata tingkat kepentingan dan nilai rata-rata tingkat kinerja yang diperoleh dengan membaginya dengan jumlah responden (petani sampel). Nilai rata-rata tingkat kepentingan dan tingkat kinerja masingmasing atribut benih padi varietas PB 42 yang telah diperoleh kemudian dijumlahkan untuk didapatkan nilai rata-rata total kepentingan dan kinerja dengan dengan cara membaginya dengan jumlah atribut.

Tabel IV.20. Perhitungan Importance Performance Analysis (IPA)

\begin{tabular}{|l|c|c|}
\hline \multicolumn{1}{|c|}{$\begin{array}{c}\text { Atribut Produk } \\
\text { (Benih PB 42) }\end{array}$} & $\begin{array}{c}\text { Tingkat Kepentingan } \\
(\text { Yi) }\end{array}$ & $\begin{array}{c}\text { Tingkat Kinerja } \\
(\mathrm{Xi})\end{array}$ \\
\hline Produktivitas & 2.34 & 2.44 \\
\hline Ketahanan Terhadap HPT & 2.63 & 2.53 \\
\hline Tahan Rontok & 2.91 & 2.56 \\
\hline Daya Tumbuh & 4.09 & 4.03 \\
\hline Tahan Rebah & 4.22 & 4.13 \\
\hline Kualitas Beras & 2.53 & 2.56 \\
\hline Umur Panen & 2.69 & 2.59 \\
\hline Bentuk Tanaman & 2.25 & 2.31 \\
\hline Volume Benih dalam kemasan & 2.34 & 2.59 \\
\hline Kemasan yang menarik & 2.34 & 2.53 \\
\hline Harga beli benih & 2.63 & 2.31 \\
\hline Ketersediaan benih & 2.59 & 2.34 \\
\hline Promosi & 2.34 & 2.34 \\
\hline Skor Rata-Rata & 2.76 & 2.71 \\
\hline
\end{tabular}

\section{Sumber: Lampiran 8}

Skor rata-rata tingkat kepuasan sebesar 2,71 berarti petani sampel menyatakan kurang puas terhadap atribut yang melekat pada benih padi PB42. Hasil diagram kartesius berdasarkan Gambar 3 untuk petani pengguna benih padi varietas PB 42 dapat dilihat pada Tabel berikut.

Tabel IV.21. Hasil Diagram Katersius benih padi varietas PB 42

\begin{tabular}{|l|l|l|l|}
\hline KUADRAN I & KUADRAN II & KUADRAN III & KUADRAN IV \\
\hline
\end{tabular}




\begin{tabular}{|l|l|l|}
\hline & Daya Tumbuh & Kemasan \\
Tahan Rebah & Volume Kemasan \\
& Promosi \\
& Harga \\
Bentuk Tanaman \\
Produktivitas \\
Umur Panen \\
Ketahanan HPT \\
Ketersediaan \\
Bentuk Tanaman \\
Kualitas Beras
\end{tabular}

Hasil analisis berupa posisi masingmasing atribut pada empat kuadran adalah sebagai berikut:

\section{Prioritas Utama (Kuadran I)}

Kuadran I menunjukkan bahwa tingkat kepentingan dari variabel di anggap penting oleh petani sampel, tetapi kinerja dari variabel ini dianggap biasa saja dan kurang memuaskan responden. Tidak ada atribut pada kuadran ini.

\section{Pertahankan Posisi (Kuadran II)}

Atribut-atribut yang termasuk kuadaran II menunjukan dimana tingkat kepentingan dan tingkat kinerja tinggi, sehingga responden merasa puas. Atribut-atribut yang termasuk dalam kuadran ini adalah tahan rebah dan daya tumbuh.

Tahan rebah dan daya tumbuh merupakan faktor yang dianggap penting oleh para petani tetapi kinerja benih tersebut masih rendah sehingga belum bisa memuaskan para petani, dengan demikian variabel ini harus menjadi prioritas utama bagi perusahaan untuk meningkatkan kepuasan petani.

Tahan rebah merupakan faktor penting agar tanaman padi dapat tumbuh dan berproduksi secara maksimal. Ketahanan rebah benih padi varietas PB 42 berada pada level sedang, untuk itu petani berharap atribut tahan rebah benih padi PB 42 kinerjanya ditingkatkan oleh perusahaan penangkar.

Daya tumbuh benih padi varietas PB 42 cukup bagus, hal ini terlihat dari banyak benih yang tumbuh di lapangan, tetapi bila dihubungkan dengan stok benih padi PB 42 di kios saprotan dan pertanian terlalu berlebihan sehingga petani mendapatkan benih padi stok lama yang mempunyai daya tumbuh yang mulai turun.

\section{Prioritas Rendah (Kuadran III)}

Kuadaran III merupakan atribut yang dianggap kurang penting oleh responden dan kinerja pada atribut ini juga kurang begitu diperhatikan, karena atribut-atribut pada kuadran III merupakan atribut-atribut yang tidak berpengaruh terhadap kepuasan petani sampel. Atribut-atribut yang termasuk pada kuadran III ini adalah kemasan, volume kemasan, promosi, harga, ketahanan terhadap hama/penyakit, bentuk tanaman, kualitas beras, ketersediaan benih dan umur panen padi varietas PB 42 . Begitu banyak atribut benih padi PB 42 yang berada pada kuadran III menunjukkan bahwa benih varietas bukan lagi menjadi pilihan utama petani padi di lokasi penelitian.

\section{Berlebih (Kuadran IV)}

Atribut yang berada pada kuadaran IV ini adalah atribut yang dianggap tidak penting oleh petani tetapi kinerja dari benih tersebut sangat berlebihan. Tidak ada atribut yang berada pada kuadran IV ini.

\section{Customers Satisfaction Index (CSI)}

Nilai weighted factors digunakan untuk menghitung weighted score. Nilai weighted sore didapat dari nilai perkalian antara weighted factor dengan nilai rata-rata kinerja setiap atribut. Nilai indek kepuasan petani sampel/konsumen (CSI) diperoleh dari total weighted score dibagi lima (banyaknya skala yang digunakan) dan dikalikan 100 persen. Hasil perhitungan indeks kepuasan petani sampel (CSI) terhadap benih padi varietas PB 42 dapat dilihat pada Tabel berikut. 


\begin{tabular}{|c|c|c|c|c|}
\hline \multirow[b]{2}{*}{ Atribut Produk } & $\begin{array}{c}\text { Rata-Rata Skor } \\
\text { Kepentingan }\end{array}$ & $\begin{array}{l}\text { Weigth } \\
\text { Factors }\end{array}$ & $\begin{array}{l}\text { Rata-Rata Skor } \\
\text { Kinerja }\end{array}$ & $\begin{array}{l}\text { Weigth } \\
\text { Score }\end{array}$ \\
\hline & (MIS) & (WF) & (MSS) & (WS) \\
\hline Produktivitas & 2.34 & 0.044 & 2.44 & 0.11 \\
\hline \multirow{2}{*}{$\begin{array}{l}\text { Ketahanan Terhadap HPT } \\
\text { Tahan Rontok }\end{array}$} & 2.63 & 0.050 & 2.53 & 0.13 \\
\hline & 2.91 & 0.055 & 2.56 & 0.14 \\
\hline Daya Tumbuh & 4.09 & 0.077 & 4.03 & 0.31 \\
\hline Tahan Rebah & 4.22 & 0.080 & 4.13 & 0.33 \\
\hline Kualitas Beras & 2.53 & 0.048 & 2.56 & 0.12 \\
\hline Umur Panen & 2.69 & 0.051 & 2.59 & 0.13 \\
\hline Bentuk Tanaman & 2.25 & 0.043 & 2.31 & 0.10 \\
\hline Volume dalam kemasan & 2.34 & 0.044 & 2.59 & 0.11 \\
\hline Kemasan yang menarik & 2.34 & 0.044 & 2.53 & 0.11 \\
\hline Harga beli benih & 2.63 & 0.050 & 2.31 & 0.11 \\
\hline Ketersediaan benih & 2.59 & 0.049 & 2.34 & 0.11 \\
\hline \multirow[t]{2}{*}{ Promosi } & 2.34 & 0.044 & 2.34 & 0.10 \\
\hline & 35.90 & 0.679 & 35.26 & 1.93 \\
\hline \multicolumn{5}{|c|}{$\mathrm{CSI}=(\mathrm{WS} / 5) \times 100 \% \quad 38.547 \%$} \\
\hline \multicolumn{2}{|c|}{$\begin{array}{l}\text { Customers Satisfaction Index (CSI) secara } \\
\text { keseluruhan menunjukan bahwa nilai indeks } \\
\text { kepuasan petani padi terhadap benih padi } \\
\text { varietas PB } 42 \text { yaitu sebesar } 38,547(0,38547) \text {. } \\
\text { Nilai CSI } 38,547 \text { ini berada pada rentang indeks } \\
\text { kepuasan antara } 0.20(20 \%) \text { sampai dengan } \\
0,40(40 \%) \text { ini berarti bahwa para petani padi }\end{array}$} & \multicolumn{3}{|c|}{$\begin{array}{l}10.000 \mathrm{~m}^{2} \text { sebanyak } 6 \text { petani }(18,75 \%) \text {. } \\
\text { 2. Berdasarkan hasil perhitungan indeks } \\
\text { kepuasan konsumen (CSI) petani responden } \\
\text { sebesar } 38,547 \%(0,3854) \text { artinya secara } \\
\text { keseluruhan menyatakan kinerja benih padi } \\
\text { varietas PB } 42 \text { kurang memuaskan petani di } \\
\text { lokasi penelitian. }\end{array}$} \\
\hline
\end{tabular}

Saran anerja benih padi varietas PB 42, hal ini juga menunjukan bahwa atribut-atribut yang ada pada benih padi varietas PB 42 sudah mulai kalah dibandingkan dengan benih varietas yang baru baik dari produsen yang sama maupun dari produsen yang lain. Varietas PB42 bila dibandingkan dengan varietas Ciherang, Mekongga, Impari dan lainnya kalah dalam hal ketahanan terhadap hama penyakit, produksi dan rasa nasi kurang enak.

\section{KESIMPULAN DAN SARAN}

\section{Kesimpulan}

1. Karakteristik petani sampel di lokasi penelitian kelompok umur berkisar antara 46-51 tahun sebesar $40.63 \%$. Pendidikan petani sampel sebagian besar responden adalah Iulusan Sekolah Dasar sebesar 65,63 $\%$. Kisaran pendapatan terbanyak sebesar Rp. 1,1 juta s.d. Rp. 3,0 juta per musim tanam sebesar 56,26\%. Pengalaman ratarata petani sampel menanam padi PB 42 yaitu 12,13 tahun. status lahan sebagai pemilik yaitu sebanyak 25 orang $(78,13 \%)$, sisanya sebanyak 7 orang (21,88 \%) sebagai petani penggarap saja. Luas lahan garapan 1.000 s.d. $5.500 \mathrm{~m}^{2}$ sebanyak 26 petani

1. Perlu adanya monitoring terhadap ketersediaan benih padi varietas selain PB 42 di kios-kios pertanian, sehingga petani dapat memperoleh benih padi yang berkualitas sehingga petani dapat memperoleh pendapatan yang layak.

2. Petani perlu mempertimbangkan pemakaian benih PB 42 yang banyak mempunyai kelemahan kinerja atributnya dan dapat beralih ke benih padi varietas lain sesuai dengan rekomendasi dinas pertanian setempat.

\section{DAFTAR PUSTAKA}

Anonymous, 2014. Potensi Pertanian Kecamatan Manyak Payed dalam Angka 2014.

Anonymous. 2007. Karakteristik Benih Padi di Indonesia. Deptan. Jakarta

Bagio Mudakir, 2011. Jurnal. Produktivitas Lahan dan Distribusi Pendapatan Berdasarkan Status Penguasaan Lahan pada Usahatani Padi (Kasus di Kabupaten Kendal Jawa Tengah), 
Fakultas Ekonomika dan Bisnis Universitas Diponegoro Semarang

Elys Fauziyah, 2011. Jurnal: Manajemen Resiko Pada Usahatani Padi Sebagai Salah Satu Upaya Dalam Mewujudkan Ketahanan Pangan Rumah Tangga Petani, Prodi Agribisnis Fakultas Pertanian Universitas Trunojoya, Bangkalan

Engel.J.F, R.D. Blackwel, dan P.W. Miniard. 1995. Perilaku Konsumen Jilid I.Bina Aksara. Jakarta .

Kotler, P. 2002. Manajemen Pemasaran, Jilid dua, Edisi Millennium. PT. Prenhallindo.Jakarta.

Mears, L.A. 1982. Era Baru Perberasan Indonesia. Yokyakarta. UGM

N.M.C.Laksmi, I.K. Suamba, I.G.A.A Amabarawati, 2010, E-Journal Agribisnis dan Agrowisata ISSN: 2301-6523 Vol. 1, No. 1, Juli $2012 \quad 34$ http://ojs.unud.ac.id/index.php/JAA Analisis Efisiensi Usahatani Padi Sawah (Studi Kasus di Subak Guama, Kecamatan Marga, Kabupaten Tabanan)Program Studi Agribisnis, Fakultas Pertanian, Universitas Udayana

Nurlaila, Zuraida.A, Jaelani A., 2012, Analisis Pendapatan Usahatani Padi (Oryza Sativa, L), Benih Varietas Ciherang Yang Bersertifikat dan Tidak Bersertifikat Di Kecamatan Labuan Amas Selatan
Kabupaten Hulu Sungai Tengah, Jurnal, Media Sains, Vol.4 No. 1, BSN 20853548,Univ. Islam Kalimantan

Rangkuti, 2006. Measuring Costumers Satisfaction. Gramedia Pustaka. Jakarta

Simamora, B. 2004. Panduan riset prilaku konsumen. PT Gramedia pustaka, Jakarta

Sumarwan, U. 2002. Perilaku Konsumen: Teori dan Penerapanya Dalam Pemasaran. Ghalia Indonesia. Jakarta .

Soetopo L.1993. Teknologi Benih. Jakarta; Rajawali Pers.

Peter, J. Paul dan Olson, Jerry C. 1999. Perilaku Konsumen dan Strategi Pemasaran, Alih bahasa Damos Sihombing. Jakarta: Erlangga.

Wirawan, Baran dan Wahyuni, S. 2002. Memproduksi Benih Bersertifikat. Penebar Swadaya. Jakarta.

Wirawan dan Sri. 2002. Memproduksi Benih Bersertifikat: Padi, Jagung, Kedelai, Kacang Tanah, Kacang Hijau. PT Penebar Swadaya., Jakarta.

Zacky, E. 2005. Pengadaan dan Pengolahan Benih Jagung Manis (Zea mays accharata sturt) diUnit Pengolahan Benih Pt. Sang Hyang Seri (Persero) Malang Jawa Timur. Laporan Praktek Lapang. Fakultas Pertanian. Institut Pertanian Bogor 